\title{
TRAVEL SURVEY INSTRUMENT DESIGN INTEGRATING RESIDENTIAL LOCATION CHARACTERISTICS AND SURVEY ADMINISTRATION FOR KOCHI CITY, INDIA
}

Krishnapriya Molath Gopi ${ }^{1}$, Soosan George Thanelimalil ${ }^{2}$, Matha Venkata Lakshmi Ranga

Anjaneyulu ${ }^{3}$

${ }^{1,2}$ Civil Engineering Department, Mar Athanasius College of Engineering, Kerala, India

${ }^{3}$ Civil Engineering Department, National Institute of Technology, Calicut, Kerala, India

Received 1 March 2018; accepted 7 April 2018

\begin{abstract}
Data collection for transportation studies is a real challenge faced by the researchers and engineers in a developing country. This paper focused on design of travel survey instrument integrating the residential location characteristics, sample design and pilot survey did using household interview method for Kochi region of India. Survey instrument was standardised from initial pilot survey and the modified diary is again tested against nonresponse. Quality of the collected data could be controlled efficiently by using the household interview method and its efficient execution. The response rate of household interview method for data collection was given priority as it has direct influence on the accuracy of the results. From the pilot survey experience it was evident that the response rate of the household interview method can be increased with the help of a response facilitator. Experience and problems faced during the data collection was also discussed.
\end{abstract}

Keywords: survey instrument design, residential location characteristics, data collection, survey design, response facilitator, developing country.

\section{Introduction}

Travel Demand Models accurately linking individual activity patterns and the travel environment will be critical to sustain the development of a reliable and efficient transportation system for a city. However, relatively few studies have applied the activity-based framework to investigate relationships between various long-term individual decisions, such as residential, work location, public vehicle preference and one's daily activity patterns (Glickman et al., 2015). Among these the residential location characteristics can be one of the significant factors that can determine the activity and travel patterns of household members. Improvement of travel models can be done only by widening the parameters studied by activity-travel survey. It can be achieved through modification of conventional survey instrument. For a developing country, the travel survey design and survey administration is a real challenge faced by the researchers. A survey method with high response rate and good quality data is also remaining as a barrier for efficient data collection. In most of the developed

\footnotetext{
${ }^{1}$ Corresponding author: krishnapriyamg@mace.ac.in
} 
countries the data required is derived from census data which has the disadvantage of limiting the number of variables for the analysis.

The objective of the study is to identify survey instrument format integrating residential location characteristics and survey technique to collect good quality data from households. Factors that can increase the response rate of household interview method are also studied within time and monetary constrains. Based on the findings from the pilot survey, data from 2,993 households are collected successfully from surveying a total of 3,107 households, using the modified survey instrument.

\subsection{Relevant Literature}

The hindrance in implementing the activity based models in many countries is due to non-availability of required data for the model development. Attitudinal and statedpreference extensions to conventional household surveys can overcome this defect. Widening of explanatory variables for mode choice, destination choice etc. can also increase the accuracy of conventional models (Petersen and Vovsha, 2006). There is a strong impact of Built Environment characteristics like residential location, work place location and road network on activity-travel behavior. Good land use mix can decrease the motorized trips and traffic congestion. Household locations determine the demand for community facilities and services including transportation systems. To a significant extent, these location choices determine the activity and travel patterns of household members (Bhat and Guo, 2006). “One's place of residence serves as a spatial anchor, impacting the spatial and temporal attributes of one's movements"(Habib and Kockelman, 2008).
Nowadays all research works on travel demand modeling are focusing on the impact of land use on travel behavior. Within 'homogeneous' groups of individuals such as age, income etc. there may be preferences for travel modes (especially car or public transport), and these may have an impact on the influence of land use on travel behavior. There is hardly any literature on preferences for model choices within the so called homogeneous groups of people and on the impact of these preferences on public vehicle usage, frequency of activities, etc. People with a preference for public transport include public transport accessibility in their residential choice. Preferences for modes have a significant impact on the number of trips, as well as on the distance travelled by mode. The omission of preferences for modes may result in an overestimation of the impact of land use on travel behavior (Van Wee et al., 2002).

Inefficient land use control and weak political will result in changing urban landscape and land use patterns in response to socioeconomic demands of the growing population but not necessarily according to plan. Although, metropolitan authority has noticed the region's self-evolving and expanding urban structure, it has failed to cope and address the risks associated with its urbanization. Distance to be travelled by each commuter for different activities, frequency of activities and mode choice for the trips can be considerably influenced by where these commuters reside. The longer they need to travel will in turn raise the consumption of fuel and energy which causes increase in air pollution and degradation of the environment (Rivera and Tiglano, 2005).

Residential location is one of the driving forces of urban dynamics. It impacts 
employment, economic development, social structure, spatial segregation, and the transport system. Understanding and modeling residential location in travel behavior is a primary concern for urban planners, policy makers, and researchers (Schirmer et al., 2014). Mobility and lifestyle decisions, such as residential location, employment, automobile ownership, and activity participation, which are more fundamental decisions, influence everyday activity participation (Glickman et al., 2015).

The research studies in the area of discrete choice residential and travel demand models were done with an aim to improve the forecasting quality of urban land use and travel (Ben Akiva and Bowman, 1998). In Western Australia the work on modeling the relationship between residential location and mode choice within a behavioral analysis framework was conducted. It resulted in the conclusion that improving the accessibility of public transport can change the mode choice of individuals (Nurlaela and Curits, 2012). An integrated model on residential location, workplace location and vehicle ownership was developed to find it's the influence on the commute tour characteristics. The characteristics like workplace density, residential location densities, household income, number of workers, number of adults and number of vehicles owned by the household were taken as independent variables of analysis. The study reached on the conclusion that the residential location and work place location characteristics have impact on the tour characteristics and mode choice of an individual (Paleti et al., 2013).

The people in a developing country like India preferred to reside at home and ready to commute long distances for different activities. According to the $69^{\text {th }}$ round of the National Sample Survey conducted among major Indian states in 2012, urban Kerala is second only to urban Maharashtra in the proportion of households for which the maximum distance travelled by any earner to reach the place of work was more than five kilometers (Goswami et al., 2015). All the above studies show the importance of using activity based modeling in travel demand modeling and also the need for inclusion of location characteristics. The studies from household survey data can add additional variables and can develop more realistic models than models from census data. The integration of residential location characteristics will add a new dimension to the existing activity based models.

\section{Study Area}

Kochi Municipal Corporation (KMC), the heart of Kerala state in India, is the region selected for the present study and is shown in Fig. 1. Kochi is one of the few cities in India which is well connected by the four major modes of transport say road, rail, water and air transport. Kochi is the industrial and commercial capital of Kerala state. Kochi Metro is a major development that facilitates commuting within the urban agglomeration. Kochi is remarked as the "Gateway to Kerala", one of the most visited cities in India (Kerala sustainable urban Development project report, 2005). Fort Kochi was the first municipality formed in India in 1664, under Dutch. Kochi Municipal Corporation was formed on $1^{\text {st }}$ November 1967 merging Fort Kochi, Mattanchery and Ernakulum Municipalities. The Kochi Municipal Corporation is spread over $94.88 \mathrm{~km}^{2}$ and it is divided into 74 electoral divisions. As per provisional reports of Census (2011c) India, population of Kochi in 2011 is 602,046. Literacy rate of $\mathrm{KMC}$ is $97.31 \%$, which is 
very high compared to any other major cities of India. With population density of 6345 persons per $\mathrm{km}^{2}, \mathrm{KMC}$ is the most densely populated corporation in the state. It is $5^{\text {th }}$ among the 20 major cities selected under Smart City Mission of Government of India.

The residential area is evenly distributed within KMC. The land use characteristics of KMC shows almost $75.77 \%$ of usable area is under residential use, which is not a preferred characteristic for a metropolitan region. The increased land use for residential purpose is acting as a hindrance for further development of the city. The percentage of land use for transportation purpose is only $5.83 \%$, which is very low for such a densely populated city, resulting in narrow roads and heavy traffic congestion problems in KMC (Development plan of Kochi City region 2031, Vol. 1, 2010). Table 1 shows the existing land use pattern of KMC.



Fig. 1.

Study Area

\section{Table 1}

Existing Land Use Pattern of KMC

\begin{tabular}{|l|l|}
\hline Land Use Specification & \multicolumn{1}{|c|}{$\begin{array}{c}\text { Existing \% } \\
\text { (Gross) }\end{array}$} \\
\hline Residential & 53.13 \\
\hline Commercial & 2.23 \\
\hline Public and semi public & 4.69 \\
\hline Industrial & 1.83 \\
\hline Transportation & 5.83 \\
\hline Park and open space & 0.70 \\
\hline Hazardous & - \\
\hline Others & 4.19 \\
\hline Paddy / wet land & 4.65 \\
\hline Dry cultivation / Agriculture & 0.11 \\
\hline Water Bodies & 22.64 \\
\hline Total & 100 \\
\hline
\end{tabular}

Source: (Development plan for Kochi City, 2010) 


\section{Survey Instrument and Travel Survey Design}

\subsection{Survey Instrument Design}

Survey instrument should be designed according to the details needed from the travel survey and method adopted for data collection. The diary should be comfortable for both enumerators and respondents to provide correct information in both directions. The ease in recording the communicated data is also considered in the diary design. Considering the socioeconomic characteristics of the study area and variables identified for analysis the survey instrument was initially designed (Diary1) as simple as possible for household interview method. The details to be collected were arranged under specific headings, namely; household, personal, residential location characteristics, telecommunication usage, future metro usage and activity-travel attributes.

Dairyl was started with household and personal characteristics. Household characteristics such as name of household head, contact details, division number, type of dwelling unit, number of males and females in the house, details of vehicle ownership etc. form the initial part of the diary. Following this, the personal characteristics like relationship with household head, gender, age, education, occupation, type of employment, income per month, possession of driving license etc. were included.

Residential location characteristics that are likely to influence the travel pattern and mode choice of individuals were identified from literature survey and considering the study area characteristics. The details like reason for selecting present location, distance to main road, nearest bus stop, distance to usual shopping center, distance to city center and frequency of public transport available for work, education, shopping and city center were included. A closed end question was provided to record the reason for less preferring the public transport. Frequency of shopping in a week by each household was also included. Telecommunication is an option to participate in activities without traveling. The clear picture about the usage of telecommunication is not available for different levels of people in the study area. Extent of telecommunication usage of each household was also measured using the diary. The work of Kochi metro rail, that connects different parts of KMC, is in progress. Considering the anticipated usage of metro rail for different activities, a small Stated Preference extension was also included in the diary. It included distance to metro station from place of residence, probable mode of transportation to metro station, number of metro users in future and purpose of metro usage.

Activity-travel part was designed in such a way that it can give the details of complete travel and activity pattern of all the persons in a household. Attributes like origin and destination of each trip, travel time, mode used, cost of travel, activity involved, starting and finishing time of each activity, accompanying household or non-household members and frequency of each trip in a week were included. It was designed to collect activity- travel pattern of a previous usual working day and a previous holiday. The coding used for employment type, mode and type of activity were printed in the diary itself, so that it will be convenient to the enumerators to record the data with less writing during survey and to reduce the error while recording. 


\subsection{Travel Survey Design}

Sample size determination and survey method are the important aspects in survey design. Sufficient care was taken to select the optimum sample size. The total number of households in $\mathrm{KMC}$ is $1,58,535$ as per 2011census of India. For calculation of the sample size the population is assumed to be normally distributed and the standard equation for calculating sample size for random sampling is used (shown in Eq. (1) and Eq. (2)).

$n=\frac{Z^{2} p(1-p) / e^{2}}{1+\frac{Z^{2} p(1-p)}{e^{2} N}}$

Simplified form of the equation is:

$n=\frac{Z^{2} p(1-p)}{e^{2}}$
Where $\mathrm{n}=$ sample size for finite population; $\mathrm{N}=$ population size; $\mathrm{Z}=$ statistical parameter corresponding to confidence level ( $\mathrm{Z}$ is 1.96 for $95 \%$ confidence interval); e = desired margin of error (adopted as 5\%).The value of $\mathrm{n}$ is calculated using both equations and is multiplied by a design effect 2 and is increased by $5 \%$ for contingency. The value of $\mathrm{p}$ is taken from previous studies conducted by LSGD Research wing of Kerala Government at Kochi Municipal Corporation. The sample size is calculated using equation (1) and (2) and the maximum value was taken. In most of the travel survey studies the value of sample size is selected as more than $1.5 \%$ of total population, as the accuracy of the model will increase considerably with increase in sample size. Especially for activity based modeling there should be enough number of samples as the models need to predict the travel behaviour at individual level, and not at an aggregate level. The calculated values of sample size are given in table 2 .

Table 2

Sample Size Calculation

\begin{tabular}{|l|c|}
\hline Different criteria foe sample size calculation & $\begin{array}{c}\text { Number of } \\
\text { households }\end{array}$ \\
\hline Sample size based on age structure & 1899 \\
\hline Sample size based on mode choice & 1926 \\
\hline $1.5 \%$ of total household & 2421 \\
\hline Selected sample size & 3000 \\
\hline
\end{tabular}

Thus the total sample selected was 3000 household (1.89\% of total population). Multi stage random sampling method was adopted, as the sample size is big and survey area is large. If interviews are being conducted in a small number of relatively well-defined areas, it is easier to maintain a higher degree of quality control on the conduct of the interviews for large sample size. KMC is divided into 74 electoral divisions. These divisions are stratified according to population density. The land use characteristics of the study area are such as it is allocated uniformly over the entire area. To prevent the chance of clustering of sample on geographical basis, 32 divisions were selected according to the distance from the City Center as shown in Fig. 2. The number of households from each division was selected by means of Probabilities Proportional to Size (PPS). Total household number in each division was taken from 
Census (2011a) Hand Book. Households were selected randomly from the 32 divisions considered for survey.

Experience from other researchers in developing countries and literature have a strong support to select the household interview method for data collection, on basis of high response and good quality data (Manoj and Verma, 2015; Muralidhar et al., 2006). The response rate of the survey is crucial as it have direct effect on the final results (Stopher, 1992). The response rate and quality of data collected was determined by the method of survey adopted. Studies by Richardson et al., 2005; Stopher, 1992; Stopher and Greaves, 2007; etc. mentioned that household interview provide factual demographic and travel attributes. This survey method also possesses the advantages like higher response rate, considerable flexibility for questioning and answering, attitudes, opinions etc. and shorter time span compared to self-completion surveys.



Fig. 2.

Division Map of Kochi Municipal Corporation with Selected Divisions for Survey 
The help of a response facilitator can considerably increase the response rate of household interview method in a high literate area (Richardson et al., 1995). A consent letter for the survey from Kochi Mayor was issued from Kochi Municipal Corporation office and its copy was given to all the enumerators, which helped a lot to convince the people about originality and need of the survey. The Councillors (people's representatives of a division) of each division were informed before conducting the survey, as per the direction form Mayor. The activity-travel pattern of those who start and end the activity chain at the place of residence in a working day was recorded. Those who are not residing permanently at their home and those who are staying some other places for job or education were avoided. Individuals were asked for the activity-travel pattern for a usual preceding working day and holiday. The surveys were conducted only on weekends and public holidays so that there would be more chance to meet the eligible persons at their houses. The personal activity-travel patterns were recorded by asking from the corresponding individuals for more precision if they were available at home during survey. If not available it was recorded by asking to other eligible members of the family.

\section{Pilot Survey}

Pilot survey can be conducted by spending 5-10 per cent of total budget allocated for the main survey (Richardson et al., 1995). Enumerators were well trained on the usage of survey instrument and told about the significance of each data entry before the survey. Male and female enumerators were engaged for conducting the survey. Self-presence of the researcher as one of the enumerators helped to maintain a higher degree of quality control on the conduct of the interviews at field. 158 samples were collected from 6 different divisions. 98 samples were collected using Diaryl and 60 samples were collected using modified diary. There were 6 and 2 non-responses in both cases respectively.

\subsection{Modified Diary}

After collecting 98 samples using Diary1, the diary was studied again based on the (non)response rate and survey experience; and required alternations were made. GPS coordinates were added along with the household characteristics which can add further details on residential location characteristics if needed. One of the high non-responses among the personal information was income per month. Instead of asking the income directly they were asked to tell the income group as per the coding in the travel diary. The questions of residential location characteristics were changed to column format from row format. The column format is more efficient in recording the data for the enumerators (Rastogi and Rao, 2002). The options for closed end questions were changed as per the information obtained from the pilot survey. As the non-response to the holiday travel pattern was more, it is decided to eliminate from the survey. It also decreased the burden over surveyor and respondent by decreasing the survey time per household. Usage of more than one mode for a particular trip was found often along the survey. So the activity- travel part was modified with provision to include up to three modes, its travel time and travel cost separately in a single trip. Different parts of the modified survey instrument for collecting specific information, like personal, residential location characteristics etc. are shown in Fig. 3. 


\begin{tabular}{|c|c|c|c|c|c|c|c|c|c|c|c|}
\hline \multicolumn{12}{|c|}{ 2. Pencalal laformation } \\
\hline \multicolumn{2}{|c|}{ S1:So } & Persen 1 & Persca 2 & Persen 3 & \begin{tabular}{l|l|} 
Pernon 4 & \\
\end{tabular} & Persed 5 & Persen 6 & \multirow[t]{2}{*}{ Person? } & \multirow[t]{2}{*}{ Person 8} & \multirow[t]{2}{*}{ Person9 } & \multirow[t]{2}{*}{ Persoe 10} \\
\hline \multicolumn{2}{|c|}{ Bchitioeship with bead of the Hif } & HH & & & & & & & & & \\
\hline \multicolumn{12}{|l|}{ Geadet } \\
\hline \multicolumn{12}{|l|}{$A g$} \\
\hline \multicolumn{12}{|l|}{ Bdacatiso } \\
\hline \multicolumn{12}{|l|}{ Decupation } \\
\hline \multicolumn{12}{|c|}{ Irme of erganization } \\
\hline \multicolumn{12}{|c|}{ Dpe of emplosment } \\
\hline \multicolumn{12}{|c|}{ income per meath } \\
\hline \multicolumn{12}{|l|}{ Driving licesse } \\
\hline \multicolumn{12}{|c|}{ Veticle walable fot exatustur ase } \\
\hline $\begin{array}{l}\text { Type of } \\
\text { Enployment }\end{array}$ & $\begin{array}{l}\text { Gort } \\
\text { Employee(GE) }\end{array}$ & $\begin{array}{l}\text { Fivate } \\
\text { Eesployze( (N) }\end{array}$ & \multicolumn{2}{|c|}{$\begin{array}{l}\text { SelfEngloged } \\
\text { (SE) }\end{array}$} & $\begin{array}{l}\text { Dely Wages } \\
\text { (DW) }\end{array}$ & \begin{tabular}{|l} 
Retind \\
$(\mathbb{R})$
\end{tabular} & \multicolumn{2}{|c|}{$\begin{array}{l}\text { Hose Maker } \\
\text { (Ii) }\end{array}$} & \begin{tabular}{|l} 
Sodeat \\
(5)
\end{tabular} & \multicolumn{2}{|c|}{$\begin{array}{l}\text { Seckigg Employmett } \\
\text { (SK) }\end{array}$} \\
\hline \multicolumn{2}{|c|}{ Iscome monet: $1<10,000$} & $0,000-20,0$ & 3.20 & $000 \cdot 30,000$ & 4.300 & $000-50,000$ & $5.50,00$ & $0-75,000$ & 675,0 & 0.-1lach & 7.21 lakh \\
\hline
\end{tabular}



\begin{tabular}{|c|c|c|c|c|c|c|c|c|c|c|c|c|c|c|c|c|c|c|c|}
\hline \multicolumn{20}{|c|}{ 4. Metro tsage in latere } \\
\hline \multicolumn{7}{|c|}{ Distance ts matro etritice $\quad \ldots \quad . \quad \mathrm{km}$} & \multicolumn{13}{|c|}{  } \\
\hline \multicolumn{6}{|c|}{ Pampes for atichmetro will bo used: I Work } & & \multicolumn{2}{|c|}{ 2Fbucatice } & \multicolumn{2}{|c|}{3 stoppiag } & \multicolumn{4}{|c|}{ 4Roctuation } & \multicolumn{3}{|c|}{ 5Roligigat } & & \\
\hline \multicolumn{20}{|c|}{ Ka. of metro users ia fitart: } \\
\hline \multicolumn{5}{|c|}{ Freq̧ueacy of botingmetro: Doily } & \multicolumn{3}{|c|}{ retilly } & \multicolumn{3}{|c|}{ cect inassota } & \multicolumn{4}{|c|}{ occasivedly } & \multicolumn{3}{|c|}{ skret } & & \\
\hline \multicolumn{20}{|c|}{ 5ACIIVITY DUARY } \\
\hline \multicolumn{20}{|c|}{ DAY1 (Worlibg ky) } \\
\hline \multirow[t]{2}{*}{ Fence } & \multirow[t]{2}{*}{ Tilss } & \multirow[t]{2}{*}{ otipe } & \multirow[t]{2}{*}{$\begin{array}{c}\text { tret of } \\
\text { stant }\end{array}$} & \multirow[t]{2}{*}{ Dedan: } & \multirow{2}{*}{$\begin{array}{l}\text { Taxt } \\
\text { of } \\
\text { rad }\end{array}$} & \multicolumn{2}{|c|}{ Unalatse } & \multicolumn{2}{|c|}{  } & \multirow{2}{*}{$\begin{array}{l}\text { Ditanct } \\
\text { (k) }\end{array}$} & \multicolumn{3}{|c|}{ 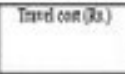 } & \multirow[t]{2}{*}{$\begin{array}{l}\text { Type of } \\
\text { ativing }\end{array}$} & \multirow{2}{*}{$\begin{array}{l}\text { Adtivh } \\
\text { sarhy } \\
\text { tex }\end{array}$} & \multirow{2}{*}{$\begin{array}{l}\text { Attih } \\
\text { ofing } \\
\text { itst }\end{array}$} & \multicolumn{2}{|c|}{  } & \multirow{2}{*}{$\begin{array}{l}\text { Propesy } \\
\text { of the rip } \\
\text { in a and }\end{array}$} \\
\hline & & & & & & $\mathrm{Mn} \mathrm{M}$ & $2 \mathrm{NB}$ & $\pi$ & II 73 & & $\mathrm{Cl}$ & $\mathrm{c}_{2}$ & $\mathrm{C} 3$ & & & & 国 & $\mathrm{NH}$ & \\
\hline & $\operatorname{tsp} 1$ & Hoese & & & & & & & & & & & & & & & & & \\
\hline & thp? & & & & & & & & & & & & & & & & & & \\
\hline & 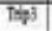 & & & & & & & & & & & & & & & & & & \\
\hline
\end{tabular}

Fig. 3.

Different Parts of Modified Survey Instrument for Collection of Specific Information

\subsection{Sample Characteristics}

In pilot survey, a total of 158 houses were surveyed from six different divisions. Eight households showed unwillingness for survey. 150 households have 624 individuals and total number of trips is 925 . Number of trips per person is found to be 1.48. Average number of persons per household is 4.16 and female male ratio is 1059. Driving license is possessed by $34.78 \%$ of people. Among the literate people, $27.88 \%$ have qualification as degree and more 
and $17.25 \%$ have Pre Degree or Diploma and $54.88 \%$ have Matriculation or lower. Only $3.21 \%$ of the total population above age 5 is illiterate. $7.37 \%$ of population has age below 5 years, $20.67 \%$ has age between $6-20$ years, $51.44 \%$ comes in $21-55$ years age group and $20.51 \%$ have age above 55 years.

The household sample contain high, medium and low income group of people. The distribution of sample population according to occupation is shown in Table 3. Among the employed persons the major share is for private employees and minimum for government employees. Table 4 shows the comparison of population characteristics as per Census (2011b) and sample characteristics. The sample characteristics are showing close resemblance with the population characteristics.

Table 3

Distribution of Population According to Occupation

\begin{tabular}{|l|c|c|}
\hline Type of occupation & Number of persons & Percentage \\
\hline Self Employed & 67 & 10.74 \\
\hline Private employee & 96 & 15.38 \\
\hline Government Employee & 23 & 3.69 \\
\hline Daily wages & 53 & 8.49 \\
\hline Seeking employment & 8 & 1.28 \\
\hline Student & 149 & 23.88 \\
\hline Home maker & 194 & 31.09 \\
\hline Retired & 34 & 5.45 \\
\hline
\end{tabular}

Table 4

Comparison of Population and Sample Characteristics

\begin{tabular}{|l|c|c|}
\hline Population characteristics & $\begin{array}{c}\text { Present Study } \\
\text { (Year 2017) }\end{array}$ & $\begin{array}{c}\text { Census Data } \\
\text { (Year 2011 ) }\end{array}$ \\
\hline Literacy Rate (\%) & 96.79 & 97.31 \\
\hline Workers (\%) & 38.30 & 38 \\
\hline Sex Ratio & 1.059 & 1.028 \\
\hline Persons per Household & 4.16 & 3.99 \\
\hline
\end{tabular}

\section{Discussion on Survey Experience}

\subsection{Nonresponse Analysis}

Nonresponse analysis was done for the collected data to evaluate the survey instrument and method of survey adopted for the present study. The total response rate of more than $80 \%$ is considered to be satisfactory for household survey (Richardson et al., 1995). The response rate using Dairylis $93.878 \%$ and it is $96.67 \%$ for the modified diary. The overall response of the pilot survey is $94.94 \%$, which give the adopted method of survey is satisfactory for the main survey. The different reasons for nonresponses observed are eligible person was present in the house but unwilling to share the required data for the survey, house closed, eligible person out and contact again. The respondents were not ready to share their personal information was the main reason for unwillingness to participate in the survey. The non-awareness of 
respondents about activity- travel survey was also another difficulty to make them convince about the data requirement of the survey.

Respondents were confused when asked about their household and personal characteristics for a 'Travel Survey'. Respondents were also arguing about some security reasons for disclosing their travel pattern. All these were to be overcome by the enumerators for successful conduct of the survey. The number of nonresponses recorded for each of the reasons were tabulated and given in Table 5. It can be observed that the major cause for nonresponse is the unwillingness of the respondent to participate in the survey. The causes of nonresponse like house closed, eligible person out, contact again was comparatively less due to the conduction of the survey only on weekends and holidays. In most of the houses more than one eligible member were present which supported data quality improvement, as the surveys were conducted only on holidays.

Table 5

Nonresponse Analysis

\begin{tabular}{|l|c|}
\hline \multicolumn{1}{|c|}{ Reason for nonresponse } & No. of household \\
\hline Successfully collected & 150 \\
\hline Showed unwillingness & 8 \\
\hline House closed & 5 \\
\hline Eligible person out & 3 \\
\hline Contact again & 1 \\
\hline Form lost & 0 \\
\hline
\end{tabular}

The response rate of household interview method for different studies conducted for research purpose in different parts of India is given in Table 6 . The other methods used for data collection like Drop-off and pickup method, telephone interview method etc. was resulting in a very low response rate than household interview method
(Manoj and Verma, 2015; Muralidhar et al., 2006; Rastogi and Rao, 2002).Present study, with modified diary, is showing highest response rate. It is evident that the participation of response facilitator and reduction in average interview time had increased the response rate of household interview method.

Table 6

Comparison of Response Rate for Household Interview Method

\begin{tabular}{|l|c|}
\hline Different Studies & Response percent \\
\hline IIT Bombay, 2002 & 74.29 \\
\hline IIT Bombay, 2006 & 89.71 \\
\hline IISC Bangalore, 2015 & 85.71 \\
\hline Present study, Diary1 & 93.88 \\
\hline Present study, with Modified Diary & 96.67 \\
\hline
\end{tabular}




\subsection{Problem of Missing Data}

The problem of missing data also is a parameter used to analyze the data collection method and instrument format. Table 7 shows the overall response rate in percentage of different characteristics in Diaryl and Modified Diary. In household characteristics the nonresponse was comparatively less. In personal characteristics main nonresponse is on personal income. It is modified by using coding than directly asking for their income, and thus increased the response rate. For residential location characteristics the modifications from row format to column format have decreased the missing data in filled diary. In case of travel characteristics, missing data is more on travel distance and travel cost of private vehicles. Travel distance can be completed by using GIS tools as the destination of each trip is recorded, which will considerably increase the response rate of travel characteristics up to $90 \%$. The travel characteristics on holidays in Diary 1 have highest nonresponse, as the household members showing unwillingness after a particular duration of survey or they were not able to recollect the activity-travel pattern one week before.

\section{Table 7}

Percent Overall Response to Different Characteristics

\begin{tabular}{|l|c|c|c|c|c|c|}
\hline \multicolumn{1}{|c|}{ Section } & \multicolumn{3}{|c|}{ Diary 1 } & \multicolumn{3}{c|}{ Modified Diary } \\
\hline & $\begin{array}{c}\text { Completely } \\
\text { filled }\end{array}$ & $\begin{array}{c}\text { Partially } \\
\text { filled }\end{array}$ & $\begin{array}{c}\text { Non } \\
\text { response }\end{array}$ & $\begin{array}{c}\text { Completely } \\
\text { filled }\end{array}$ & $\begin{array}{c}\text { Partially } \\
\text { filled }\end{array}$ & $\begin{array}{c}\text { Non } \\
\text { response }\end{array}$ \\
\hline Household characteristics & 90.82 & 3.06 & 6.12 & 93.33 & 3.33 & 3.33 \\
\hline Personal characteristics & 84.69 & 9.18 & 6.12 & 90.00 & 6.67 & 3.33 \\
\hline $\begin{array}{l}\text { Residential Location } \\
\text { characteristics }\end{array}$ & & & & & & \\
\hline 1. Row format & 88.78 & 4.08 & 7.14 & - & - & - \\
\hline 2. Column format & - & - & - & 93.33 & 3.33 & 3.33 \\
\hline Future metro usage & 84.69 & 5.10 & 10.20 & 91.67 & 3.33 & 5.00 \\
\hline Activity-travel characteristics & & & & & & 26.67 \\
\hline 1. On working day & 63.27 & 28.57 & 8.16 & 70.00 & 23.33 \\
\hline 2. On Holiday & 38.78 & 29.59 & 31.63 & - & & - \\
\hline
\end{tabular}

The overall response on different characteristics is mode for the modified questionnaire. The use of column format has helped in the data entry efficiency and speed of enumerators. Average interview duration is considered as an indicator of burden on the respondent and also on the enumerator. The average duration of interview was 17.365 minutes using Diaryl and it has reduced to 12.376 minutes using the modified diary. Two tailed t-test for mean of the two samples are done at $95 \%$ significance level. Calculated t-value is 6.775 and $t$-critical is 1.692 . So the null hypothesis is rejected and average interview duration is a significantly lower for the modified diary. The reduction in interview time is a result of modification of travel diary and experience of enumerators, which have also reduce the cost of survey. 


\section{Important Findings and Conclusions}

The findings from survey instrument design and pilot survey experience are listed below:

1. The high response rate for the survey was due to the incorporation of the response facilitator and pre information to Councillors of each division;

2. Many of Household members were willing to participate in the survey only after confirming with their Councillors, as they were exposed to some fake surveys earlier;

3. The conduct of the survey only on weekends and public holidays increased the chance of meeting eligible household members during the survey;

4. The study did not face any issues from political or religious side. Only unawareness of activity-travel survey caused some confusion for the household members;

5. Employing qualified and trained enumerators facilitated high response rate. Ability of the enumerators to communicate in local language and English increased the response rate and decreased the chance of partially filled questionnaires;

6. Self-participation of the researcher in data collection enhanced the confidence of enumerators and also resulted in better control at the field;

7. Household members were well aware of the travel time but the distance to destination was not known for some commuters. In such cases the destination was recorded properly so that the distance travelled can be calculated by using GIS tools;

8. The average interview time using the modified diary was significantly less, which in turn increased the overall efficiency of the survey;
9. The contact efficiency of the enumerators increased with experience and each enumerator was able to collect data from an average of 21 households each day.

\subsection{Limitations}

Other methods of household survey like drop-off and pick-up method, telephone interview method etc., are not considered as these methods result comparatively high nonresponse and low quality data in Indian conditions. The advanced survey methods like internet survey, computer assisted personal interview etc., are avoided due to its non-feasibility in a developing country. The methods to improve response of household interview method by giving incentives on survey response are not studied due to financial constraints.

\subsection{Conclusions}

Residential location characteristics that are likely to influence the travel behaviour of commuters are integrated in the conventional travel diary for a developing country. The role of response facilitator is the main reason for high response rate in the household interview. In a high literate metropolitan region the survey response can be increased by convincing the need of survey through their Mayor and Councillors. In fact it can also increase the quality of data obtained from each household. The reduction in duration of interview also increases the response rate of household interviews.

\section{Acknowledgements}

The authors sincerely thank the financial support received from Mahatma Gandhi University, Government of Kerala, India. The authors are also grateful to the Mayor 
and Councillors of Kochi Municipal Corporation and enumerators for supporting the data collection.

\section{References}

Ben-Akiva, M.; Bowman, J. L. 1998. Integration of an activity based model system and residential location model, Urban Studies 35(7): 1131-1153.

Bhat, C.R.; Guo, J.Y. 2006. An Innovative Methodological Framework to Analyze the Impact of Built Environment Characteristics on Activity-Travel Choices. In Conference Proceedings "Innovations in Travel Demand Modeling", Vol. 2, 137-140.

Census of India. 2011a. District Census Handbook Ernakulam, Part XII-A. Government of India. 280 p.

Census of India. 2011b. District Census Handbook Ernakulam, Part XII-B. Government of India. 516 p.

Census of India. 2011c. Analysis of Census Data, Provisional Population Totals. Government of India. $70 \mathrm{p}$.

Development Plan for Kochi City. 2010. Volume 1: Study and Analysis, Department of Town and Country Planning. Government of Kerala, India. 163 p.

Glickman, I.; Ishaq, R.; Carvel, R.K.; Shiftan, Y. 2015. Integrating activity-based travel-demand models with land-use and other long-term lifestyle decisions, Journal of Transport and Land Use 8(3): 71-93.

Goswami, B.; Kumar, N.A.; George, K.K. 2015. Patterns of commuting for Work, A case study of Kochi city, RULSG Occassional Paper: 5, Research Unit on Local Self Governments, Center for Development Studies, Thiruvanandapuram. Kerala, India. 27 p.

Habib, K.M.N.; Kockelman, M.K. 2008. Modeling the Choice of Residential Location and Home Type: Recent Movers in Austin, Texas. In $87^{\text {th }}$ Annual Meeting of the Transportation Research Board, $17 \mathrm{p}$.
Kerala Sustainable Urban Development Project. 2005. Final Report. Volume 2: City Report Kochi. Local Self Government Department. Government of Kerala, India. $127 \mathrm{p}$.

Manoj, M.; Verma, A. 2015. Design and administration of activity-travel diaries: a case study from Bengaluru city in India, Current Science 109: 1264-1272.

Muralidhar, B.; Mathew, T.V.; Dhingra, S.L. 2006. Prototype Time-Space Diary Design and Administration for a Developing Country, Journal of Transportation Engineering 132(6): 489-498.

Nurlaela, S.; Curtis, C. 2012. Modeling household residential location choice and travel behaviour and its relationship with public transport accessibility, Procedia - Social and Behavioural Sciences 54: 56-64.

Paleti, R.; Bhat, C.; Pendyala, R. 2013. Integrated Model of Residential Location, Work Location, Vehicle Ownership, and Commute Tour Characteristics, Transportation Research Record: Journal of the Transportation Research Board 2382: 162-172.

Petersen, E.; Vovsha, P. 2006. Directions of Coordinate Improvement of Travel Surveys and Models. In Proceedings of the Innovations in Travel Demand Modeling, 2: 85-88.

Rastogi, R.; Rao, K.V.K. 2002. Survey Design of Studying Transit Access Behaviour in Mumbai City, India, Journal of Transportation Engineering 128(1): 68-79.

Richardson, A.J.; Ampt, E.S.; Meyburg, A.H. 1995. Survey Methods for Transport Planning. Eucalyptus Press. University of Melbourne. Australia, 475 p.

Rivera, I.M.A.; Tiglano, N.C.C. 2005. Modeling residential location choice, work place location choice and mode choice of two - worker households in metro Manila. In Proceedings of the Eastern Asia Society for Transportation Studies, 5: 1167-1178. 
Schirmer, M.P.; Eggermond M.A.B.; Axhausen W. K. 2014. The role of location in residential location choice models: a review of literature, Journal of Transport and Land Use 7(2): 3-21.

Stopher, P.R. 1992. Use of an activity-based diary to collect household travel data, Transportation 19(2): 159-176.

Stopher, P.R.; Greaves, S.P. 2007. Household Travel Surveys: Where are we going?, Transportation Research Part A: Policy and Practice 41(5): 367-381.

Van Wee, B.; Holwerda, H.; Baren, R. 2002. Preferences for Modes, Residential Location and Travel Behaviour: the Relevance for Land-Use Impacts on Mobility, European Journal of Transport and Infrastructure Research 2(3/4): 305-316. 